\title{
Clinical diabetes care of patients with type 2 diabetes at a major tertiary care hospital in the United Arab Emirates
}

\begin{abstract}
Aim: The prevalence of type 2 Diabetes Mellitus is rapidly increasing in the United Arab Emirates (UAE), resulting in a huge burden on the healthcare economy of the country. Therefore, improvement in the standards of diabetes care is required to prevent the complications of diabetes. This study evaluated the adherence of a tertiary care hospital of the UAE to the international standards of diabetes care in order to provide clinicians with information for improving diabetes care in clinical setting.
\end{abstract}

Materials and methods: A retrospective analysis of 5\% $(n=240)$ of 4800 diabetic patients visiting the clinics was conducted in a tertiary care hospital of Al Ain, UAE. The data were collected on demographic characteristics (age, gender) and 12 clinical indicators of standards of diabetes care as per American Diabetic Association (ADA) guidelines. Chi-square tests were applied to compare standards of diabetes care with $\mathrm{CDC}$ targets. Independent t-tests and one way ANOVA were applied to measure difference in $\mathrm{HbA} 1 \mathrm{c}$ by gender and age groups respectively.

Results: Of the total 240 patients, majority were females $(58.3 \%)$ and 50-65years old $(53.5 \%)$. About $63.0 \%$ of patients were obese and $56.2 \%$ had HbA1c above 7 . Hospital significantly exceeded the CDC targets in blood glucose $(95.0 \%, \mathrm{p}=0.00)$, HbAlc monitoring $(98.0 \%, p=0.00)$, \pm detailed eye examination $(77.0 \%, p=0.001)$ and blood pressure control $(57.0 \%, \mathrm{p}=0.39)$. However, the hospital significantly fell below the target of achieving HbA1c $<7(38.0 \%, \mathrm{p}=0.00)$ and foot examination $(59.0 \%$, $\mathrm{p}=0.006)$. Poor diabetes control $(\mathrm{HbAl} \mathrm{c}>7)$ was significantly $(\mathrm{p}=0.007)$ associated with obesity. The proportion of poor diabetes control was slightly higher $(p=0.421)$ in patients $>60$ years and females $(\mathrm{p}=0.603)$

Conclusion: The study highlighted the importance of adhering to diabetes care standards of ADA. Diabetes care could be further improved with more effort from diabetes care team, managing obesity and by improving patients' education and selfcare.

Keywords: diabetes care indicators, clinical diabetes care, tertiary care hospital
Volume 2 Issue I - 2015

\author{
Bachar Afandi,' Azhar Ali Malik, ${ }^{2}$ Juma \\ AlKaabi, ${ }^{3}$ Ali Elhouni, ${ }^{4}$ Faisal Aziz $^{5}$ \\ 1,2,4 Division of Endocrinology, Department of Medicine, Tawam \\ Hospital in affiliation with Johns Hopkins Medicine \\ ${ }^{3}$ Associate Professor, college of medicine, AI Ain, UAE University \\ ${ }^{5}$ Institute of Public Health, College of Medicine and Health \\ Sciences, United Arab Emirates University
}

Correspondence: Azhar Ali Malik, Division of Endocrinology, Department of Medicine, Tawam Hospital in affiliation with Johns Hopkins Medicine, Al Ain, United Arab Emirates, Tel 0097I 503398204,Email aamalik06@gmail.com

Received: August 26, 2014 | Published: January 12, 2015
Abbreviations: ADA, american diabetes association; ANOVA, analysis of variance; BMI, body mass index; CDC, centre for disease control; DM, diabetes mellitus; FBS, fasting blood sugar; HbAlc, glycated haemoglobin; ICSI, institute of clinical systems improvement; IDF, international diabetes federation; MENA, middle east and north africa; NNHS, national nutrition health survey; UAE, united arab emirates

\section{Introduction}

Diabetes mellitus (DM) is a chronic disease and a major source of morbidity and mortality. The number of patients suffering from diabetes in 2013 was 382 million, a total which is expected to increase up to 592 million in $2035 .^{1}$ The prevalence of diabetes has increased dramatically all over the world., ${ }^{2,3}$ As per International Diabetes Federation (IDF) figures, 382million people have Diabetes in the world, of which more than 34.6million are in MENA (Middle east and North Africa), which is expected a rise up to 67.9 million by $2035 .{ }^{1}$ There is substantial evidence that many of the adverse outcomes of diabetes can be prevented, or at least delayed, by an aggressive programme of more preventive care, prompt identification of the problem, early intervention and treatment. ${ }^{4,5}$

According to IDF, United Arab Emirates is one of the most vulnerable countries in the world with a high prevalence of type 2 diabetes. In age group of 20-79years, the prevalence of Diabetes is approximately $10.2 \% .^{1}$ In 2007 , Saadi and co-workers reported that age standardized rates of diabetes (diagnosed and undiagnosed) and pre-diabetes in Al Ain city was $29.0 \%$ and $24.2 \%$ respectively. ${ }^{6}$ The number of undiagnosed diabetes patients is 30,360 . The total number of death in age group of 20-79 years is 1,385 , while mean expenditure due to diabetes per person is $2,228 \mathrm{US}$ dollars. ${ }^{1}$

Diabetes clinical studies in the UAE either used a small sample size, ${ }^{7}$ or produced inconclusive results. ${ }^{8}$ These studies reported modest improvements in some key indicators of diabetes care. One clinical intervention study published in 2012 has shown improvement in two diabetes care indicators (glycated haemoglobin and blood pressure control). Results of this interventional study were generally positive and emphasized the feasibility of improving the current clinical practice and the need of further research to understand the long term impact of structured approach to improve the quality of type 2 Diabetes care in the UAE. ${ }^{9}$ 
A study conducted on 651 patients in Kingdom of Saudi Arabia reported that mean $\mathrm{HbAlc}$ was $9.0 \pm 2.0 \%$, mean fasting plasma glucose was $9.9 \pm 3.9 \mathrm{mmol} / \mathrm{L}$, and mean 2 hour postprandial plasma glucose was $15.0 \pm 5.3 \mathrm{mmol} / \mathrm{L}$. In $20.6 \%$ of patients the $\mathrm{HbA} 1 \mathrm{c}$ level was less than $7 \% .{ }^{10}$ Another study conducted in Riyadh, Saudi Arabia reported that $39.0 \%$ of the patients achieved overall ADA targets of Diabetes care with fasting blood glucose $21.8 \%$, HbA1c $55.5 \%$ and LDL-C $55.5 \%$. The study concluded that ADA standards of diabetic care were not met in most of diabetic patients, indicating that these standards are easy to preach than to practice. ${ }^{11}$

The aim of this study was to explore the current diabetes care standards in type II diabetes patients at tertiary care hospital and compare practices with international standards.

\section{Materials and methods}

We conducted a retrospective analysis of records of type II diabetes patients who had attended diabetes clinics at a tertiary care hospital of Al Ain, United Arab Emirates in 2013. Al Ain is an Emirate of Abu Dhabi, United Arab Emirates with a population of approximately 400,000 . The study was conducted in diabetes polyclinic of a tertiary care hospital providing health services to the population of the AlAin eastern region. The study participants included patients having confirmed diagnosis of type II diabetes mellitus with age of 18years and above. A total number of 4800 patients fulfilled our criteria. We selected a random sample of 240 patients $(5 \%)$ from the total number of patients.

A tool was developed based on the prioritised aims and measures of Institute of Clinical Systems Improvement (ICSI) and finalized by diabetes team. ${ }^{12}$ A reporting tool using agreed data definitions was completed for each patient on 12 clinical indicators for diabetes management. The Data analysis was made in compliance with measurement specification of the ICSI guidelines. Remedial measures were undertaken based on recommendations from local guidelines. We gathered data on characteristics of patients i.e. gender and age, Body Mass Index (BMI) andtwelve diabetes care clinical indicators such as Glycated Haemoglobin (HbA1C), blood pressure, aspirin, foot examination, referral for dilated eye examination, self-monitoring of fasting blood glucose levels (FBS), advice on diet, advice on exercise, referral to the nutritionist and smoking status. The study was approved by the ethical committee of Faculty of Medicine, United Arab Emirates University, Al Ain, and United Arab Emirates.

The data were stored in Microsoft Excel and transferred to SPSS version 21 for statistical analysis. Both descriptive and inferential statistics were applied in statistical analysis. In descriptive statistics, average and standard deviations were calculated for continuous variables such as age, Glycated Haemoglobin (HbA1c), Body Mass Index (BMI) and Fasting Blood Sugar (FBS). Frequencies and percentages were computed for categorical variables of age, BMI and $\mathrm{HbAlc}$ categories, gender and standards of diabetes care. In inferential statistics, independent t-tests were run to measure differences in average BMI, FBS and $\mathrm{HbAlc}$ in gender and one way analysis of variance (ANOVA) by age categories. Chi-square tests were used to compare standards of diabetes care with centre for diseases control (CDC) 2000 goals and levels of HbA1c with BMI categories. Further, the comparison of $\mathrm{HbAl} \mathrm{c}$ with BMI was stratified by gender and age group to reduce confounding and effect modification.

\section{Results}

Average age of 240 patients was $57.9 \pm 14$.1years. Of the total patients, $22.5 \%$ were equalor less than 50 years old, $52.5 \%$ were $50-65$ years old and $25.0 \%$ were equal and above 65 years. The majority of patients were females $(58.3 \%)$ were females (Table 1$)$. Average $\mathrm{HbA1c}$ of patients was $7.85 \pm 1.7$, FBS $9.70 \pm 4.3$ and BMI was $31.3 \pm 7.4$. The majority of patients were obese $(56.2 \%)$, while $26.7 \%$ were overweight. Most of the patients had had HbAlc above $7(62.1 \%)$ and above one third of patients $(37.9 \%)$ had HbA1c less than 7 (Table 1).

In standards of diabetes care, $\mathrm{HbA} 1 \mathrm{c}$ was monitored twice a year for $99.0 \%$ of patients, smoking status $95 \%$ and foot examination for $59.2 \%$ of the patients. Detailed eye examination was conducted in $77.1 \%$ and blood glucose levels were monitored in $95 \%$ of the patients. The BMI of all patients was documented. About $98.0 \%$ of the patients were given advice on exercise and diet each and $54.2 \%$ were referred to nutrition counselling. Only $37.9 \%$ of the patients had HbAlc less than or equal to 7 and $52.1 \%$ had blood pressure less than $130 \mathrm{mmHg}$. To see the descriptive statistics on standards of diabetes care (Table 1).

Table I Descriptive statistics of baseline characteristics and standards of Diabetes care in patients $(\mathrm{N}=240)$

\begin{tabular}{lll}
\hline Variables & Frequency/Mean & $\% / \pm$ SD \\
\hline Age(years) & 57.9 & \pm 14.1 \\
Age-Cat & & \\
$<50$ years & 54 & 22.5 \\
$50-65$ years & 126 & 52.5 \\
$\geq 65$ years & 60 & 25
\end{tabular}

\section{Gender}

\begin{tabular}{lcc} 
Male & 100 & 41.7 \\
Female & 140 & 58.3 \\
HbAIc(\%) & 7.85 & \pm 1.7 \\
HbAIc - Cat & 91 & 37.9 \\
$\leq 7$ & 151 & 62.1 \\
$>7$ & 9.7 & \pm 4.3 \\
Fasting blood Sugar(mmol/L) & 31.3 & \pm 7.4 \\
BMI(Kg/m $\left.{ }^{2}\right)$ & & \\
BMI-Cat & 41 & 17.1 \\
Normal & 64 & 26.7 \\
\hline Overweight & 135 & 56.2 \\
\hline Obese & & 99 \\
Standards of diabetes care* & & \\
HbAlccheck twice a year & 238 & \\
\hline
\end{tabular}


Table Continued.

\begin{tabular}{lll}
\hline Variables & Frequency/Mean & $\% / \pm$ SD \\
\hline Smoking status documentation & 228 & 95 \\
Foot examination documentation & 142 & 59.2 \\
\hline Dilated eye examination & 185 & 77.1 \\
Self-monitoring blood glucose levels & 228 & 95 \\
BMI documentation & 240 & 100 \\
Advice on diet & 235 & 98 \\
Advice on Exercise & 235 & 98.2 \\
Nutrition Referral & & 54.2 \\
HbAlc $\leq 7$ & 130 & 37.9 \\
SBP $<$ I30mmHg & & 54 \\
\hline
\end{tabular}

Categorical variables were presented as frequencies and percentages

Continuous variables were presented as means and \pm standard deviations

$\mathrm{SD}$, standard deviation, $\mathrm{HbAlc}$, glycated haemoglobin, BMl, body mass index, SBP, systolic blood pressure

*American Diabetic Association (ADA) standards of diabetes care
Average HbA1c, FBS and BMI were compared with gender and age groups. No significant difference was found in average HbA1c and FBS in gender and age groups. However, average BMI was higher in 50-65years old patients $(\mathrm{p}=0.023)$ and females $(\mathrm{p}=0.007)$ (Table 2$)$.

Table 3 shows the comparison of glycaemic control with BMI, age groups and gender. The percentage of patients with poor diabetes control $(\mathrm{HbA} 1 \mathrm{c}>7)$ significantly $(\mathrm{p}=0.007)$ increased with increase in BMI i.e. proportion of poor diabetes control in patients with normal BMI was $41.5 \%$, overweight $65.6 \%$ and obese was $68.1 \%$. Similarly, the proportion of poor diabetes control was higher in patients older than 65years, but the increase was insignificant $(\mathrm{p}=0.421)$. Likewise, the prevalence of poor diabetes control was slightly higher $(p=0.603)$ in females versus their male counterparts. Further, glycated haemoglobin levels were compared with BMI in strata of gender and age groups. Across all age groups, the proportion of patients with poor diabetes control was the highest in obese patients. In addition, the highest proportion of poor diabetes control was observed in the obese eldest age group. Within gender, the obese males (79.5\%) had the highest proportion of poor diabetes control as compared to the patients who were overweight $(57.6 \%)$ or normal (30.4\%). However, the prevalence of poor diabetes control was maximum in overweight $(74.2 \%)$ females, followed by obese $(62.6 \%)$ and normal BMI $(55.5 \%)$.

In comparison of diabetes care standards with CDC, Tawam hospital significantly exceeded the target in majority of its standards i.e. self-reported monitoring of blood glucose $(95.0 \%, \mathrm{p}=0.000)$, HbAlc test twice a year $(98.0 \%, \mathrm{p}=0.000)$, detailed eye examination $(77.0 \%, \mathrm{p}=0.001)$ and blood pressure control $(57.0 \%, \mathrm{p}=0.59)$. However, the hospital substantially fell below (20.9\%) the target of achieving $\mathrm{HbA} 1 \mathrm{c}<7(37.9 \%, \mathrm{p}=0.00)$ and comprehensive foot examination $(59.0 \%, \mathrm{p}=0.006)$ (Table 4$)$.

Table 2 Comparison of average Glycated Haemoglobin, Fasting Blood Glucose and Body Mass Index with gender and age groups (N=240)

\begin{tabular}{|c|c|c|c|c|c|c|c|}
\hline \multirow[t]{2}{*}{ Variables } & \multirow[b]{2}{*}{$\mathbf{N}$} & \multicolumn{2}{|l|}{ HbAlc(\%) } & \multicolumn{2}{|c|}{ FBS(mmol/L) } & \multicolumn{2}{|l|}{$\operatorname{BMI}\left(\mathbf{K g} / \mathbf{m}^{2}\right)$} \\
\hline & & Mean士SD & P-value & Mean $\pm S D$ & P-value & Mean $\pm S D$ & P-value \\
\hline All & 240 & $7.9 \pm 1.7$ & -- & $9.7(4.7)$ & -- & $31.3 \pm 7.4$ & -- \\
\hline \multicolumn{8}{|l|}{ Age(years) } \\
\hline$<50$ years & 54 & $8.1 \pm 2.2$ & 0.538 & $10.6 \pm 6.2$ & 0.154 & $30.7 \pm 9.1$ & 0.023 \\
\hline $50-65$ years & 126 & $7.8 \pm 1.7$ & & $9.7 \pm 4.3$ & & $32.5 \pm 7.5$ & \\
\hline$\geq 65$ years & 60 & $7.8 \pm 1.3$ & & $8.9 \pm 3.7$ & & $29.4 \pm 5.0$ & \\
\hline \multicolumn{8}{|l|}{ Gender } \\
\hline Male & 100 & $7.9 \pm 1.8$ & 0.666 & $9.5 \pm 5.1$ & 0.521 & $29.8 \pm 7.7$ & 0.007 \\
\hline Female & 140 & $7.8 \pm 1.7$ & & $9.9 \pm 4.5$ & & $32.4 \pm 7.1$ & \\
\hline
\end{tabular}

HbAIc, glycated haemoglobin, FBS, fasting blood sugar, BMI, body mass index, SD, standard deviation Independent t-test was performed to estimate differences in average $\mathrm{HbAIc}, \mathrm{FBS}$ and BMI by gender. One way ANOVA was performed to estimate differences in average HbAIc, FBS and BMI by age groups. P-values $\leq 0.05$ were considered as statistically significant for both ANOVA and t-test 
Table 3 Comparison of Glycated Haemoglobin with Body Mass Index, overall and by age groups and gender $(\mathrm{N}=240)$

\begin{tabular}{|c|c|c|c|c|}
\hline Variables & & HbAlc $\leq 7$ & HbAlc>7 & P-value \\
\hline & $\mathbf{N}$ & Freq (\%) & Freq (\%) & $\leq 0.05$ \\
\hline Overall & 240 & $89(37.1)$ & $151(62.9)$ & \\
\hline \multicolumn{5}{|l|}{ BMI $\left(\mathrm{Kg} / \mathrm{m}^{2}\right)$} \\
\hline Normal & $4 I$ & $24(58.5)$ & $\mid 7(4 \mid .5)$ & 0.007 \\
\hline Overweight & 64 & $22(34.4)$ & $42(65.6)$ & \\
\hline Obese & 135 & 43(31.9) & $92(68.1)$ & \\
\hline \multicolumn{5}{|l|}{ Age (years) } \\
\hline Age $<50$ years & 54 & $21(38.9)$ & $33(6 I . I)$ & 0.421 \\
\hline Age 50-65years & 126 & $50(39.7)$ & $76(60.3)$ & \\
\hline Age $\geq 65$ years & 60 & $18(30.0)$ & $42(70.0)$ & \\
\hline \multicolumn{5}{|l|}{ Gender } \\
\hline Male & 100 & $39(39.0)$ & $6 I(6 \mid .0)$ & 0.601 \\
\hline Female & 140 & $50(35.7)$ & $90(64.3)$ & \\
\hline \multicolumn{5}{|l|}{ Age (years) } \\
\hline \multicolumn{5}{|l|}{ Age $<50$ years } \\
\hline \multicolumn{5}{|l|}{$\operatorname{BMI}\left(\mathrm{Kg} / \mathrm{m}^{2}\right)$} \\
\hline Normal & 15 & $10(66.7)$ & $5(33.3)$ & 0.001 \\
\hline Overweight & 12 & $0(0.0)$ & $12(100.0)$ & \\
\hline Obese & 27 & I I (40.7) & 16(59.3) & \\
\hline \multicolumn{5}{|l|}{ Age $50-65$ years } \\
\hline \multicolumn{5}{|l|}{ BMI $\left(\mathrm{Kg} / \mathrm{m}^{2}\right)$} \\
\hline Normal & 16 & $10(62.5)$ & $6(37.5)$ & 0.006 \\
\hline Overweight & 30 & I4(46.7) & $16(53.3)$ & \\
\hline Obese & 80 & $26(32.5)$ & $54(67.5)$ & \\
\hline \multicolumn{5}{|l|}{ Age $\geq 65$ years } \\
\hline \multicolumn{5}{|l|}{$\mathrm{BMI}\left(\mathrm{Kg} / \mathrm{m}^{2}\right)$} \\
\hline Normal & 10 & $4(40.0)$ & $6(60.0)$ & 0.059 \\
\hline Overweight & 22 & $8(36.4)$ & $14(63.6)$ & \\
\hline Obese & 28 & $6(2 \mid .4)$ & $22(78.6)$ & \\
\hline \multicolumn{5}{|l|}{ Gender } \\
\hline \multicolumn{5}{|l|}{ Males } \\
\hline \multicolumn{5}{|l|}{ BMI $\left(\mathrm{Kg} / \mathrm{m}^{2}\right)$} \\
\hline Normal & 23 & $16(69.6)$ & $7(30.4)$ & 0.002 \\
\hline Overweight & 33 & |4(42.4) & $19(57.6)$ & \\
\hline Obese & 44 & $9(20.5)$ & $35(79.5)$ & \\
\hline \multicolumn{5}{|l|}{ Females } \\
\hline \multicolumn{5}{|l|}{$\mathrm{BMI}\left(\mathrm{Kg} / \mathrm{m}^{2}\right)$} \\
\hline Normal & 18 & $8(44.4)$ & $10(55.5)$ & 0.147 \\
\hline Overweight & 31 & $8(25.8)$ & $23(74.2)$ & \\
\hline Obese & 91 & $34(37.4)$ & $57(62.6)$ & \\
\hline
\end{tabular}

HbAlc, glycated haemoglobin; BMI, body mass index

It was categorized according to CDC-2000 guidelines. Normal: BMI $<25 \mathrm{Kg}$ / $\mathrm{m}^{2}$, Overweight: $\mathrm{BMI}=25-29.9 \mathrm{Kg} / \mathrm{m}^{2}$, Obese $=\mathrm{BMI} \geq 30 \mathrm{Kg} / \mathrm{m}^{2}$

Chi-square tests were performed to estimate association of $\mathrm{HbAlc}$ with $\mathrm{BMI}$, age and gender. $\mathrm{P}$-value $\leq 0.05$ was considered as statistically significant
Table 4 Comparison of Diabetes Care indicators of patients visiting Tawam Hospital with Centre for Disease Control targets ( $N=240)$

\begin{tabular}{|c|c|c|c|c|c|}
\hline $\begin{array}{l}\text { Diabetes care } \\
\text { indicators }\end{array}$ & $\begin{array}{l}\text { Tawam } \\
\text { hospital }\end{array}$ & $\begin{array}{l}\text { CDC } \\
\text { target }\end{array}$ & Difference & $\begin{array}{l}\mathbf{X}^{2} \\
\text { Score }\end{array}$ & P-value \\
\hline & (\%) & (\%) & (\%) & $>3.84$ & $\leq 0.05$ \\
\hline $\mathrm{HbAlc}<7$ & 38 & 58.9 & 20.9 & 12.5 & 0 \\
\hline $\begin{array}{l}\text { Comprehensive } \\
\text { foot } \\
\text { examination }\end{array}$ & 59 & 74.8 & 15.8 & 7.7 & 0.006 \\
\hline $\begin{array}{l}\text { Dilated eye } \\
\text { examination }\end{array}$ & 77 & 58.7 & -18.3 & 11.4 & 0.001 \\
\hline $\begin{array}{l}\text { Patients having } \\
\text { HbAlc test } \\
\text { twice a year }\end{array}$ & 98 & 71 & -27 & 56.8 & 0 \\
\hline $\begin{array}{l}\text { Patients with } \\
\text { controlled } \\
\text { blood pressure }\end{array}$ & 57 & 52 & -5 & 0.7 & 0.39 \\
\hline $\begin{array}{l}\text { Self-reported } \\
\text { monitoring of } \\
\text { blood glucose }\end{array}$ & 95 & 70.4 & -24.6 & 40.7 & 0 \\
\hline
\end{tabular}

HbAIc, glycated haemoglobin, CDC, centre for disease control, $X^{2}$, chi-square

Chi-square test was applied to compare clinical indicators of patients at Tawam hospital with CDC target. P-value of $\leq 0.05$ and chi square $>3.84$ were considered for statistical significance

\section{Discussion}

The majority of patients (37.1\%) included in this study could not achieve the CDC target of glycaemic control (HbAlc $<7)$. These findings were consistent with National Nutrition Health survey 1999 (NNHS), in which around $35.0 \%$ of the patients achieved the CDC target of HbAlc. ${ }^{13}$ One of the possible explanations for not meeting the desired glycaemic control is the increasing prevalence of patients with multiple co-morbidities, which complicates the management of type 2 diabetes. Another reason might be that patients with better glycaemic control are usually managed at primary care centres, whereas complicated cases are referred to the tertiary care hospital. Moreover, the low control of $\mathrm{HbAlc}$ is associated with the gradual progression of the disease over time, which was also reported by the United Kingdom prospective diabetes study. ${ }^{14}$ Another possibility for the poor control of $\mathrm{HbAlc}$ is the clinical inertia by the physicians to take appropriate and timely actions for high $\mathrm{HbAlc}$. Like $\mathrm{HbAlc}$, blood pressure control was also lower than the CDC-target. Possible explanations is the progression of the disease over time, poor compliance with medications, as well as clinical inertia, an issue associated with health care professionals, has been suggested for the suboptimal control ofblood pressure. The Canadian coalition of blood pressure control gave a non-compliance rate of $50 \%$ in its report. ${ }^{15}$

Regular fundoscopy can detect and prevent the diabetes eye complications. The figures showed excellent compliance with CDC target. Compared to the previous study conducted by Afandi et al., in which compliance of patients with detailed eye examination was lower because it was time-consuming for patient to have their eyes dilated and the examination had little importance to the patients. ${ }^{7}$ After much effort, by emphasizing on the importance of eye examinations, the percentage of patients attending the retinal clinic improved, and even exceeded the CDC targets. In addition, the percentage of patients initially attending regular foot examinations was low, due to the time 
constraints in busy clinics; moreover, most physicians felt that it was inconvenient for patients to take off their shoes and socks. The action taken to improve it was to involve a podiatrist for a regular examination and to reduce the number of patients in the physician's clinic. Most of the patients were given advice to help them stop smoking and some of them were referred to the smoking cessation clinics.

Major improvement was seen in the documentation of BMI and advice on the diet and exercise, which was given to almost every patient, because the literature revealed that advice on changing to a healthy life style can significantly improve diabetes outcomes. ${ }^{16}$ Referral to a nutritionist also improved gradually to $52 \%$ in this context. The data indicated that the majority of the patients were obese (56.2\%). A high proportion of obese patients indicate the increasing prevalence of obesity in UAE particularly in females. ${ }^{17-21}$ Another observation was that the $\mathrm{HbA} 1 \mathrm{c}$ deteriorated with increase in BMI of patients. Obese patients had poor control of diabetes as compared to the patients with normal BMI. These findings suggest that obesity has played a significant role in deterioration of HbAlc. ${ }^{17-21}$

We compared BMI with glycated haemoglobin across age group. The study did not find a clear association of poor diabetes control with either age group or gender. However obesity increased with age group and was most common in age group of 50 to $65 y$ years and again deceased after 65years because of possible decrease in lean body mass. The glycated haemoglobin deteriorated with increasing age particularly in patients of age 65 years and above. The main reason for it is the sedentary life style above age of 65 with increase in multiple co-morbidities which contribute to poor control.

\section{Limitations}

The study was conducted in a tertiary care hospital, but data on lipids, micro-albuminuria and annual influenza vaccination were not included. Moreover, referral to dental care was not included in the study.

\section{Conclusion and recommendations}

The findings of this study on diabetes care are consistent with other studies carried out in the Gulf region, Middle East and Western countries. ${ }^{22-29}$ This study highlights the importance of using diabetes standards (flow chart), which includes all the required indicators of diabetes management, as advised by international working groups like ADA. The study results were quite encouraging; however, diabetes care could be further improved with more effort from diabetes care team, improving patients' education and self-care. This study emphasizes the need for periodic monitoring of diabetes and its associated risk factors like obesity and complications. Also, there is a dire need to manage and prevent obesity, which is steadily increasing in the UAE. Further, training and education of the stake-holders is imperious to improve the quality of diabetes care at all levels of the health care system (primary, secondary and tertiary), in compliance with the policy of the UAE government.

\section{Acknowledgements}

Authors extend their acknowledgement to Hosn Osman Saif Eddine quality control officer tawam hospital, Seham El Khamdi for data collection and Ramzan Afzal of the Statistical Department of United Arab Emirates University, Al Ain, UAE for carrying out statistical analysis.

\section{Conflict of interest}

Author declares that there is no conflict of interest.

\section{References}

1. International diabetes federation (IDF). IDF Diabetes atlas. 6th ed International diabetes federation. Brussels, Belgium, Europe; 2013.

2. Amos AF, McCarty DJ, Zimmet P. The rising global burden of diabetes and its complications: estimates and projections to the year. Diabet Med. 2010;14(suppl 5):1-85.

3. King H, Aubert RE, Herman WH. Global burden of diabetes: Prevalence, numerical estimates and projections. Diabetes Care. 1998;21(9):1414-1431.

4. UK Prospective Diabetes Study Group. Intensive blood-glucose control with sulphonylureas or insulin compared with conventional treatment and risk of complications in patients with type 2 diabetes. Lancet. 1998;352(9131):837-853.

5. UK Prospective Diabetes Study Group. Tight blood pressure control and risk of macro vascular and micro vascular complications in type 2 diabetes: UKPDS38. BMJ. 1998;317(7160):703-713.

6. Saadi H, Carruthers SG, Nagelkerke N, et al. Prevalence of diabetes mellitus and its complications in a population-based sample in Al Ain, United Arab Emirates. Diabetes Res Clin Pract. 2007;78(3):369-377.

7. Afandi B, Ahmed S, Saadi H, et al. Audit of a diabetes clinic at Tawam hospital, United Arab Emirates, 2004-2005. Ann N Y Acad Sci. 2006;1084:319-324.

8. Reed RL, Revel AO, Carter A, et al. A clinical trial of chronic care diabetic clinics in general practice in the United Arab Emirates: a preliminary analysis. Arch Physiol Biochem. 2001;109(3):272-280.

9. Shehab A, Elnour A, Abdulle A. A Clinical Audit on Diabetes Care in Patients with Type 2 Diabetes in Al-Ain, United Arab Emirates. Open Cardiovasc Med J. 2012;6:126-132.

10. Al-Hussein F. Diabetes control in a primary care setting: a retrospective study of 651 patients. Ann Saudi Med. 2008;28(4):267-271.

11. Kharal M, Al-Hajjaj A, Al-Ammri M, et al. Meeting of the American Diabetes Association standards of diabetic care. Saudi J Kidney Dis Transpl. 2010;21(4):678-685.

12. Redmon B, Caccamo D, Flavin P, et al. Diagnosis and Management of Type 2 Diabetes in adults. Institute for Clinical Systems Improvement. 2014.

13. UK Prospective Diabetes Study Group. Tight blood pressure control and risk of macro vascular and micro vascular complications in type 2 diabetes: UKPD S 38. BMJ. 1998;317(7160):703-713.

14. Thomas J, Edward W, Joel E, et al. Is glycaemic control improving in US adults? Diabetes care. 2008;31(1):81-86.

15. Chockalingam A, Bacher M, Camphell N, et al. Adherence to management of high blood pressure: recommendations of the Canadian Coalition for High Blood Pressure Prevention and Control. Can J Public Health. 1998;89(5):15-111.

16. World Health Organization. Global strategy on diet, physical activity and health. 2004;25(3):292-302.

17. Badrinath P, Al-Shboul QA, Zoubeidi T, et al. Measuring the health of the nation: United Arab Emirates health and lifestyle survey 2000. AlAin, United Arab Emirates: Faculty of Medicine \& Health Sciences and College of Business and Economics. 2002.

18. El Mugamer IT, Ali Zayat AS, Hossain MM, et al. Diabetes, obesity and hypertension in urban and rural people of Bedouin origin in the United Arab Emirates. J Trop Med Hyg. 1995;98(6):407-415.

19. Malik M, Bakir A, Saab BA, et al. Glucose intolerance and associated factors in the multi-ethnic population of the United Arab Emirates: results of a national survey. Diabetes Res Clin Pract. 2005;69(2):188-195. 
20. Pugh RN, Hossain MM, Malik M, et al. Arabian Peninsula men tend to insulin resistance and cardiovascular risk seen in South Asians. Trop Med Int Health. 1998;3(2):89-94.

21. Sheikh-Ismail LI, Henry CJ, Lightowler HJ, et al. Prevalence of overweight and obesity among adult females in the United Arab Emirates. Int J Food Sci Nutr. 2009;60(Suppl 3):26-33.

22. Khunti K, Gadsby R, Millet C, et al. Quality of diabetes care in the $\mathrm{UK}$ : comparison of published quality of-care reports with results of the quality and outcomes frame work for diabetes. Diabet Med. 2007;24(12):1436-1441.

23. Calvert M, Shankar A, McManus RJ, et al. Effect of the quality and outcomes framework on diabetes care in the United Kingdom: a retrospective cohort study. BMJ. 2009;338:1870.

24. Millett C, Car J, Eldred D, et al. Diabetes prevalence, process of care and outcomes in relation to practice size, caseload and deprivation: national cross-sectional study in primary care. JR Soc Med. 2007;100(6):275-283.
25. Saaddine JB, Cadwell B, Gregg EW, et al. Improvements in Diabetes Processes of Care and Intermediate Outcomes: United States 1988-2002. Ann Intern Med. 2006;144(7):465-474.

26. Grant RW, Buse JB, Meigs JB Quality of Diabetes Care in U. S. Academic Medical Centres: Low rates of medical regimen change. Diabetes Care. 2005;28(2):337-442.

27. Chenung BM, Ong KL, Cherny SS, et al. Diabetes prevalence and therapeutic target achievement in the United States.1999 to 2006. Am J Med. 2009;122(5):443-453.

28. Gray J, Millet CO, Sullivan C, et al. Association of age, sex and deprivation with quality indicators for diabetes: population-based cross sectional survey in primary care. J R Soc Med. 2006;99(11):576-581.

29. Youssef A, El Mahalli A, Akl O, et al. Quality of diabetes care in primary care setting in Egypt: an example of health sector reform in developing countries. J Egypt Public Health Assoc. 2006;81(5-6):301-320. 